\title{
Cabin Heat Removal from an Electric Car
}

\author{
J.C. Leong, C.-Y. Tseng, B.-D. Tsai, and Y.-F. Hsiao \\ National Pingtung University of Science and Technology, No. 1, Shuefu Road, 91201 Neipu, Pingtung, Taiwan.
}

\begin{abstract}
This work studies the feasibility of reducing the temperature in an electric car cabin through a ventilation device. The temperature and velocity fields in the cabin were simultaneously solved for through CFD means. Current results show that most of the solar irradiation energy is absorbed by the seats especially when they are directly hit by the sun beam. However, the seat temperature can be significantly brought down with the help of a ventilation device. There exists a flow rate which is sufficient enough to bring down the seat temperature.
\end{abstract}

Keywords: car cabin, solar irradiation, heat management, $C F D$.

\section{Introduction}

There are a few electric cars on the market these days. However, one of the most critical bottleneck of the electric car is its relatively short mileage per charge [1]. Although most automobile manufacturers have planed to manufacture their own versions that give better mileage, there is always room for more improvement. The power source of a running electric car is its set of batteries that provides electricity to an electric motor as well as other onboard accessories, such as the lighting system, the audio system, and the air-conditioning system. Among them, the airconditioning system consumes the most power. In order to yield the maximum mileage per charge, the usage of electric car air-conditioning system has to be made as minimal as possible [2].

According to a study related to the deaths from incidents in or around motor vehicles, it was found that as high as $34 \%$ of the fatality was caused by recklessness of the driver for leaving the kid in vehicle under hot weather [3]. As a matter of fact, the car cabin temperature will rise alarmingly and will be almost $11^{\circ} \mathrm{C}$ higher than the outside temperature if the car is parked under the blazing sun for only 10 minutes. Just in USA, an average of more than 30 children dies from hyperthermia after being left unattended in a vehicle every year.

Lin [4] applied the radiation model and Ray Tracing model to numerically investigate the flow and thermal fields inside the car cabin due to solar load. He also investigated the effects of the material and optical properties on the entire flow field. His work shows that the solar irradiation effects can be successfully simulated using the Discrete Ordinates (DO) radiation model.

Alexandrov et al. [5] have numerically studied the efficiency of a car HVAC system and addressed its main parameters including the car velocity, the air velocity, the outside temperature, the inlet air temperatures and inlet/outlet configurations. They found that the development of unfavorable zones 
of low air circulation can be controlled by modifying the inlet/outlet configurations.

In order to improve the thermal comfort of car passengers, Chien et al. [6] analyzed the transient 3D turbulent flow and thermal behaviors within a car. Moreover, their study also employed the cooling cycle analysis and conjugate heat transfer analysis at the ceiling, floor, and sides. The temperature field predicted in the car cabin compared excellently with experimental data.

This year, Al-Kayiem et al. [7] have published their experimental and numerical findings about car parked in an open space under direct sun. Their CFD simulations through FLUENT have proven the fact that most hot air gathers in the top part of the cabin due to natural heat convection from the dashboard and the rear windshield. If the front side windows were dropped down by $20 \mathrm{~mm}$, the front air gap would reduce by $20 \%$. The installation of a sunshade on the front would reduce the dashboard surface temperature dropped by $26 \%$.

In this work, the increase in temperature within a cabin due to continuous solar irradiation was investigated using FLUENT 6.2.16, a commercial CFD package. Also, the effect of heat removal from the cabin by means of an external exhaust fan system was studied.

\section{Computational Approach}

\subsection{Modeling}

The dimensions of the CFD model in this study were based on a Formosa Martiz. For simplicity, only the cabin space was considered while the frame and the glasses surrounding the space were carefully assigned with appropriate boundary conditions. The air could be reasonably assumed Newtonian and incompressible. All mechanical properties were assumed constant. To solve for the steady-state temperature distribution, the $\mathrm{k}-\varepsilon$ turbulence model has been used in conjunction with DTRM (Discrete Transfer Radiation Model)which was responsible for thermal radiation modeling. The thermal buoyancy effect that caused convection within the computational domain was modeled using Boussinesq approximation. The car was assumed located at Pingtung, Taiwan on July 21 . The times in a day considered were 11 a.m., 1 p.m., and 3 p.m.

\subsection{Governing Equations}

The governing equations involved in this study include the continuity equation, the Reynoldsaveraged Navier-Stokes equation, and the energy equation [8]. By solving these equations simultaneously, the distributions of pressure, velocity, and temperature can be obtained throughout the computational domain.

The continuity equation is expressed as

$$
\frac{\partial \bar{u}}{\partial x}+\frac{\partial \bar{v}}{\partial y}+\frac{\partial \bar{w}}{\partial z}=0
$$

whereas the Reynolds-averaged Navier-Stokes equations are expressed as

$$
\begin{aligned}
& \rho\left(\bar{u} \frac{\partial \bar{u}}{\partial x}+\bar{v} \frac{\partial \bar{u}}{\partial y}+\bar{w} \frac{\partial \bar{u}}{\partial z}\right)=-\frac{\partial \bar{p}}{\partial x} \\
& +\rho g_{x}+\mu\left(\frac{\partial^{2} \bar{u}}{\partial x^{2}}+\frac{\partial^{2} \bar{u}}{\partial y^{2}}+\frac{\partial^{2} \bar{u}}{\partial z^{2}}\right) \\
& -\rho\left(\frac{\partial \overline{u^{\prime} u^{\prime}}}{\partial x}+\frac{\partial \overline{u^{\prime} v^{\prime}}}{\partial y}+\frac{\partial \overline{u^{\prime} w^{\prime}}}{\partial z}\right) \\
& \rho\left(\bar{u} \frac{\partial \bar{v}}{\partial x}+\bar{v} \frac{\partial \bar{v}}{\partial y}+\bar{w} \frac{\partial \bar{v}}{\partial z}\right)=-\frac{\partial \bar{p}}{\partial y} \\
& +\rho g_{y}+\mu\left(\frac{\partial^{2} \bar{v}}{\partial x^{2}}+\frac{\partial^{2} \bar{v}}{\partial y^{2}}+\frac{\partial^{2} \bar{v}}{\partial z^{2}}\right) \\
& -\rho\left(\frac{\partial \overline{u^{\prime} v^{\prime}}}{\partial x}+\frac{\partial \overline{v^{\prime} v^{\prime}}}{\partial y}+\frac{\partial \overline{v^{\prime} w^{\prime}}}{\partial z}\right) \\
& \rho\left(\bar{u} \frac{\partial \bar{w}}{\partial x}+\bar{v} \frac{\partial \bar{w}}{\partial y}+\bar{w} \frac{\partial \bar{w}}{\partial z}\right)=-\frac{\partial \bar{p}}{\partial z} \\
& +\rho g_{z}+\mu\left(\frac{\partial \overline{u^{\prime} w^{\prime}}}{\partial x}+\frac{\partial \overline{v^{\prime} w^{\prime}}}{\partial y}+\frac{\partial \bar{w}^{\prime} w^{\prime}}{\partial z}\right) \\
& \left.+\frac{\partial^{2} \bar{w}}{\partial y^{2}}+\frac{\partial^{2} \bar{w}}{\partial z^{2}}\right)
\end{aligned}
$$

To bring closure to the above Reynolds-averaged Navier-Stokes equations, the k- $\varepsilon$ RNG model was employed. For this reason, two additional sets of equations must be solved simultaneously. These equations are the transport equations for turbulent kinetic energy $\mathrm{k}$ and dissipation rate $\varepsilon$. They appear to be 


$$
\begin{gathered}
\rho\left(\bar{u} \frac{\partial k}{\partial x}+\bar{v} \frac{\partial k}{\partial y}+\bar{w} \frac{\partial k}{\partial z}\right) \\
=\alpha_{k} \mu_{e f f}\left(\frac{\partial^{2} k}{\partial x^{2}}+\frac{\partial^{2} k}{\partial y^{2}}+\frac{\partial^{2} k}{\partial z^{2}}\right) \\
+G_{k}-\rho \varepsilon \\
\rho\left(\bar{u} \frac{\partial \varepsilon}{\partial x}+\bar{v} \frac{\partial \varepsilon}{\partial y}+\bar{w} \frac{\partial \varepsilon}{\partial z}\right) \\
=\alpha_{\varepsilon} \mu_{e f f}\left(\frac{\partial^{2} \varepsilon}{\partial x^{2}}+\frac{\partial^{2} \varepsilon}{\partial y^{2}}+\frac{\partial^{2} \varepsilon}{\partial z^{2}}\right) \\
+C_{1 \varepsilon}^{*} \frac{\varepsilon}{k} G_{k}-C_{2 \varepsilon} \rho \frac{\varepsilon^{2}}{\kappa} \\
\mu_{e f f}=\mu+\mu_{t} \\
\mu_{t}=\rho C_{\mu} \frac{k^{2}}{\varepsilon} \\
G_{k}=2 \mu_{t} E_{i j} \cdot E_{i j} \\
C_{1 \varepsilon}^{*}=C_{1 \varepsilon}-\frac{\eta\left(1-\eta / \eta_{0}\right)}{1+\beta \eta^{2}} \\
\eta=2 \sqrt{E_{i j} \cdot E_{i j}} \frac{k}{\varepsilon} \\
E_{i j}=\frac{1}{2}\left(\frac{\partial u_{i}}{\partial x_{j}}+\frac{\partial u_{j}}{\partial x_{i}}\right)
\end{gathered}
$$

Furthermore, the energy equation that describes the temperature field is given as

$$
\begin{aligned}
& \rho C_{p}\left(\bar{u} \frac{\partial \bar{T}}{\partial x}+\bar{v} \frac{\partial \bar{T}}{\partial y}+\bar{w} \frac{\partial \bar{T}}{\partial z}\right) \\
& =K\left(\frac{\partial^{2} \bar{T}}{\partial x^{2}}+\frac{\partial^{2} \bar{T}}{\partial y^{2}}+\frac{\partial^{2} \bar{T}}{\partial z^{2}}\right)+Q_{r a d}
\end{aligned}
$$

The parameter $Q_{\text {rad }}$ in eq. (7) refers to the heat flux due to solar irradiation.

\subsection{Condition Settings}

The details for its calculation are as follow

- Location: longitude $120.61^{\circ}$, latitude $22.64^{\circ}$

- Time zone: +8

- Date: July 21

- Time: 11:00a.m., 1:00 p.m., and 3:00 p.m.

- Weather: fair
Fig. 1 shows the grid distribution employed in this

\begin{tabular}{|c|c|}
\hline Component & Detail \\
\hline Roof & Aluminum at $328 \mathrm{~K}$ \\
\hline Windshield & Glass at $319 \mathrm{~K}$ \\
\hline $\begin{array}{l}\text { Front and } \\
\text { rear panel }\end{array}$ & $\begin{array}{l}\text { Aluminum with thermal } \\
\text { insulation condition }\end{array}$ \\
\hline Door & $\begin{array}{l}\text { Aluminum with thermal } \\
\text { insulation condition }\end{array}$ \\
\hline Floor & Thermal insulation material \\
\hline Seats & $\begin{array}{l}\text { Plastic but temperatures are } \\
\text { calculated through coupled } \\
\text { scheme }\end{array}$ \\
\hline $\begin{array}{l}\text { Cooling } \\
\text { Device }\end{array}$ & Aluminum at $328 \mathrm{~K}$ \\
\hline Exhaust Fan & $\begin{array}{l}\text { Velocity outlet at prescribed } \\
\text { velocity }\end{array}$ \\
\hline
\end{tabular}
study. For simplicity, the dashboard is purposely left out. Also from this figure, the outline of the cabin and the layout of its interior can be seen. An exhaust fan system was attached on the ceiling to dump hot air out of the cabin. For ease of consideration, the air removal mechanism is achieved through a simple curved divergent noncircular funnel-type channel. The boundaries involved in this simulation were given different names for ease of keeping track. These name and

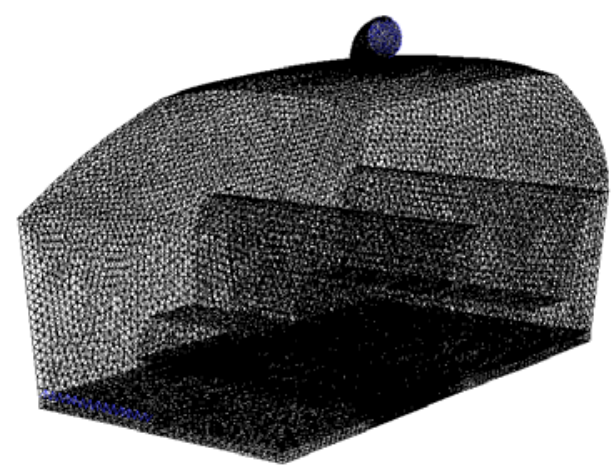

Figure 1: Distribution of grid in the Cabin.

Table 1: Boundary components and details

Table 2: Results of grid refinement test

\begin{tabular}{cc}
\hline Number of grid & Temperature $(\mathrm{K})$ \\
\hline 100,000 & 325 \\
200,000 & 326 \\
400,000 & 322 \\
600,000 & 322 \\
800,000 & 322 \\
\hline
\end{tabular}


the details for their associated settings are listed in Table 2.

A grid refinement test has been performed prior to more detailed investigation. Table 2 lists the temperature readings at a particular point in the cabin when the number of mesh in the computational domain was varied. It is evident that a grid size of 400,000 is sufficient for current study.

\section{Results and Discussion}

\subsection{Solar Irradiation at Different Time}

The temperature distributions on the symmetrical plane in the cabin are shown in Fig. 2 at 3 different times. In these cases, the cabin is facing the west.

At 11 a.m., solar thermal irradiation enters the cabin space mainly from the rear windscreen and therefore the temperature at the top portion of the rear seat back is very high. When the exhaust fan is not activated (i.e., exhaust flow rate $=0 \mathrm{~m}^{3} / \mathrm{s}$ ), as the sun gradually moves to the front at 1 p.m., thermal radiation hits on the front seat bottom directly causing its temperature to be the highest within the space. At 3 p.m., the sun has moved closer to the horizon, causing its ray to be able to hit on both the front seat bottom and front seat back. Even so, it is still clear that the rear side of the front seat back remains in temperatures lower than the front side of the front seat back.

If the exhaust fan is activated, the range of temperature within the cabin can be reduced tremendously. Even under a volume flow rate of only $0.023 \mathrm{~m}^{3} / \mathrm{s}$, the greatest air temperature could

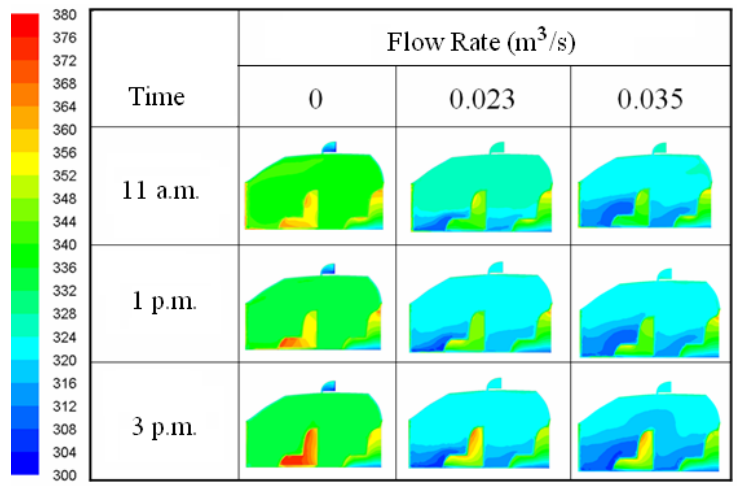

Figure 2: Temperature distribution in a west facing cabin at different times. have reduced by about $20^{\circ} \mathrm{C}$. This is evidently illustrated by the regions colored in dark blue. Clearly, as hot air is removed from the cabin, the stream of cooler air enters the cabin from the vent below the dashboard promoting an air exchange. For this reason, the temperature at the legroom is consistently lower than rest of the space within the cabin. Since the front seat is not entirely attached to the floor, the cooler air from the front legroom will gradually diffuse to the rear legroom. The presence of this additional breeze actually significantly brings down the overall temperature of the front and rear seats.

As the flow rate is further increased, the amount of heat removal is more remarkable. This is evidently proven in Fig. 2 by the fact that the regions of low temperature have grown in size and are responsible for lowering the seat temperature. Despite this fact, a tremendous increase in flow rate from $0.023 \mathrm{~m}^{2} / \mathrm{s}$ to 0.035 $\mathrm{m}^{3} / \mathrm{s}$ does not really lead to a very remarkable decrease in seat overall temperature range and distribution.

\subsection{Irradiation at Different Directions}

Another important issue to be addressed is the orientation of the cabin in association with the sun irradiation direction. Among the times considered in this study, only the temperature distributions for 1 p.m. are shown in Fig. 3.

When the cabin is facing the west, the sun is actually slightly tilted to the front allowing more solar thermal irradiation to enter the cabin through the glass of the front windscreen. If the cabin is facing the north, the sun will shine on the cabin from the west in the afternoon. At this particular



Figure 3: Temperature distribution in cabins at 1 p.m. facing west and north. 
time, the overall cabin air temperature field is found slightly greater in the north-facing cabins than that estimated for the west-facing cabins. This is directly proportional to the size of the glass through which the solar thermal irradiation penetrates. However, the temperature distributions on the frame and window glasses for the cabin facing the north are much greater than those facing the west. Once again, this figure also suggests that the temperature within the cabin can be brought down effectively with the help of an exhaust fan system.

\subsection{Effectiveness in Heat Removal}

To evaluate the effectiveness of the heat removal device, the total enthalpy and average air temperature in the cabin were evaluated and are shown in Fig. 4. When the cabin is facing the west, both the total enthalpy and average steady-state air temperature within the cabin are the greatest at 11 a.m. when compared to those at 1 p.m. and 3 p.m. This is directly related to the amount of solar thermal energy irradiated into the cabin space. Regardless of the time in a day, it seems that the effect of a flow rate of $0.023 \mathrm{~m}^{3} / \mathrm{s}$ is almost the same in terms of heat removal. Furthermore, the total enthalpy and average temperature are about the same at 1 p.m. and 3 p.m.

With the help of an active heat removal scheme, the enthalpy within the cabin may drop effectively.



Figure 4: Enthalpy and temperature variations in the west-facing cabin at different times.
However, there exists a limitation at which the enthalpy and average temperature can drop. Based on the computational results obtained in this study, it suggests that using a flow rate of $0.023 \mathrm{~m}^{3} / \mathrm{s}$ is more justifiable than a flow rate of $0.035 \mathrm{~m}^{3} / \mathrm{s}$. According to Fig. 5, the enthalpy and average temperature for a north-facing cabin are consistently greater than those for a west-facing cabin because the cabin side window glasses allow more thermal radiation to enter the cabin. For this reason, a flow rate of up to $0.035 \mathrm{~m}^{3} / \mathrm{s}$ is found to be effective in removing heat.

The results obtained in this study is believed to be very helpful in designing an exhaust fan device that is expected to cool down the cabin air which in turn cut down the dependence of the electric car users on the air-conditioning system. This measure will then surely improve the electric car mileage per charge.

\section{Conclusions}

A successful numerical study on heat removal from a car cabin has been performed in this work. The heating of car cabin depends strongly on the area of windshield or window glass through with the solar thermal energy penetrates. Hence, more solar radiative heat enters the car cabin if the car is facing north or south. Also, there exists an optimum flow rate for heat removal as both the air and seat temperatures in the cabin reduce.

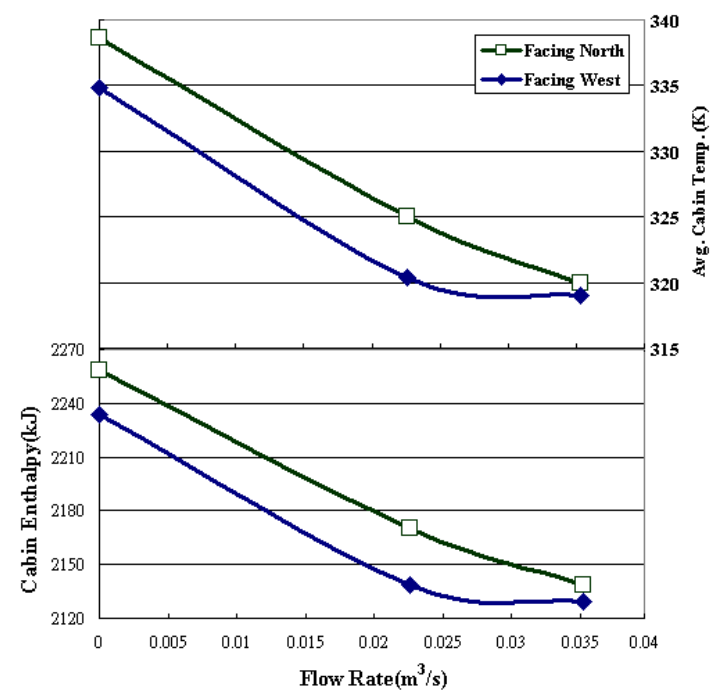

Figure 5: Enthalpy and temperature variations in the Cabin at different flow rates. 


\section{Nomenclature}

$\begin{array}{ll}C_{1 \varepsilon} & \text { constant }=1.42 \\ C_{2 \varepsilon} & \text { constant }=1.68 \\ C_{p} & \text { specific heat capacity } \\ C_{\mu} & \text { constant }=0.0845 \\ g & \text { gravitational acceleration } \\ K & \text { thermal conductivity } \\ k & \text { turbulent kinetic energy } \\ \bar{p} & \text { mean pressure } \\ Q_{r a d} & \text { heat flux due to solar irradiation } \\ S_{\varepsilon} & \text { constant }=1.42 \\ S_{\kappa} & \text { constant }=0.719 \\ \bar{T} & \text { mean temperature } \\ \bar{u} & \text { mean x-velocity component } \\ u^{\prime} & \text { fluctuation of x-velocity component } \\ \bar{v} & \text { mean y-velocity component } \\ v^{\prime} & \text { fluctuation of y-velocity component } \\ \bar{w} & \text { mean z-velocity component } \\ w^{\prime} & \text { fluctuation of z-velocity component } \\ x, y, z & \text { Cartesian coordinates } \\ \text { Greek Letters } & \text { constant }=1.39 \\ \alpha_{k} & \text { constant }=1.39 \\ \alpha_{\varepsilon} & \text { constant }=0.012 \\ \beta & \text { dissipation rate } \\ \varepsilon & \text { constant }=3.0 \\ \eta & \text { constant }=4.377 \\ \eta_{0} & \text { viscosity } \\ \mu & \text { turbulent viscosity } \\ \mu_{e f f} & \text { density } \\ \mu_{t} & \\ \rho & \text { effective viscosity } \\ & \end{array}$

\section{Acknowledgements}

The financial support of this work by the National Science Council of Taiwan under contract number NSC 98-2218-E-020-005- was greatly appreciated.

\section{References}

[1] Y. Haseo, and T. Kawashima, Basic research on a novel zero-emission public transportation system, Journal of Environment and Engineering, ISSN 1880-988X, 5(2010), 168-182.

[2] R. Farrington and J. Rugh, Impact of vehicle airconditioning on fuel economy, tailpipe emissions, and electric vehicle range, Earth Technologies Forum, Washington D.C., Oct. 31, 2000.

[3] In and around vehicle safety, Safe Kids USA, http://www.safekids.org/assets/docs/ourwork/res earch/in-and-around-cars.pdf, accessed on 201112-8.

[4] Z.-R. Lin, Combined inner and outer air flow with heat radiation to predict the thermal environment inside vehicle cabin, M.S. Thesis, National Pingtung University of Science and Technology, 2005.

[5] A. Alexandrov et. al., Analysis of flow patterns and heat transfer in generic passenger car minienvironment, the 9th Annual Conference of the CFD Society of Canada, 27 - 29 May, 2001, Kitchener, Ontario.

[6] C.H. Chien et. al., 3-D numerical and experimental analysis for airflow within a passenger compartment, International Journal of Automotive Technology, ISSN 1229-9138 (print version), ISSN 1976-3832 (electronic version), 9(2008), 437-445.

[7] H.H. Al-Kayiem et. al., Study on the thermal accumulation and distribution inside a parked car cabin, American Journal of Applied Sciences, ISSN 15469239, 7(2010), 784-789.

[8] D.C. Wilcox, Turbulence modeling for CFD, 3rd Edition, ISBN 1928729088, DCW Industries.

\section{Authors}



Jik Chang Leong received his M.S. and $\mathrm{Ph} . \mathrm{D}$. in Mechanical Engineering from the University of Oklahoma. He is now an associate professor. His recent research interests include airconditioning system, vehicle aerodynamics, and ventilation of road tunnels.

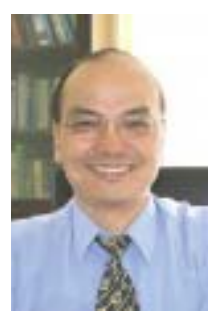

Chyuan-Yow Tseng received his M.S. and Ph.D. in Mechanical Engineering from the National Central University. He is currently a professor specialized in Fault Diagnosis and Isolation (FDI), Control and Automation Engineering, Vehicle Dynamics, and Hybrid Electric vehicles (HEVs).

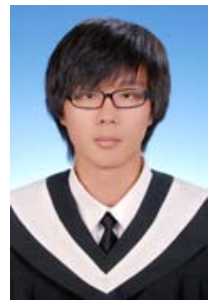

Bo-Dong Tsai received his B.S. in Vehicle Engineering from the National Pingtung University of Science and Technology. He is now a graduate student. His research interest is about energy rating of high concentration photovoltaic cells and the redesign of Fresnel lens.



Yi-Fan Hsiao received his B.S. in Vehicle Engineering from the National Pingtung University of Science and Technology. He is currently working on his M.S. degree and his research interest is in the area of fuel cell. 
